and the pulse so thready and quick, as to be scarcely discernible. Mr. Male's assistant diagnosed the case as one of acute gastritis; and, for the great depression which then existed, he prescribed an ether mixture, with 'calomel and opium, to be taken every two hours. On the following morning he was again visited, in conjunction with Mr. Male, and ras found in much the same state as on the preceding day; there was acute fixed pain in the epigastrium, increased on pressure; the same dejected countenance, the same small thready pulse, and the same coffee-coloured romiting. He was ordered to continue the pills, and an aperient was substituted for the ether.

Throughout Sunday he remained in much the same state; the pain was still fixed, and there was scarcely any tenderness, even on pressure, orer the other parts of the abdomen; the romiting still continued to distress him, and he had remitting attacks of hiccup. A blister was applied over the region of the stomach ; copious enemata were thrown up the bowels, and creasote was given with intent to allay the retchings and romitings, which were foetid and stercoraceous. There was no appreciable alteration in the symptoms up to the time of bis death on the evening of March 18th.

A post mortem examination was made the next day. On removing the sternum, it was discovered that the stomach had ascended through the osophageal opening as high as the first rib, accompanied by the omentum, and the transverse arch of the colon, which latter, doubled on itself, lay on the right side of the stomach; the left lung was entirely hidden, pressed up against the clavicle; the heart was pushed over to the right side; the diaphragm was everywhere uninjured; the oesophageal opening was slightly dilated, and so firmly embraced the stomach and colon, that no force less than that capable of tearing the parts could withdraw them. The diaphragm was divided from the sternum towards the cesophagus, and as soon as the opening was enlarged, the parts were easily retracted. There were no adhesions, and no bands. The colon and stomach lying in the thorax were highly inflamed; the stomach was partly filled with footid matter, of the consistency of gruel; and the colon contained three or four masses of what appeared to be coagulated blood, of much the same appearance as horse-dung. The parts immediately below the stricture were slightly inflamed, but the general condition of the intestines was healthy.

This accident, when diagnosed, requires the utmost watching and care on the part of the surgeon; and, should symptoms of strangulation occur, would justify an operative proceeding. "Food," says Guthrie, "should be taken slowly and in small quantities, and the patient should remain in the erect position for some time after each meal; he should carefully avoid a stooping posture at all times, as well as all muscular exertion or straining, and if strangulation occurs, an opening should be made into the abdomen, as the only means of saving life, and an attempt may be made to withdraw the hernia; but if firm adhesions have formed between the protruded part and the edges of the opening in the diaphragm, a division must be made in the most convenient situation of the stricture."

\section{BRONZED SKIN: (SUPPOSED) DISEASE OF THE SUPRARENAL CAPSULES.}

By R. Q. W Altace, Esq., Wisbech.

MRs. T., aged 48, applied to me early in March 1856. She had for some time been alarmed at observing her skin assume a yellowish tinge, with brown patches on the face and hands. Her health was otherwise much as usual; she slept and ate well, and was free from pain, but complained of lassitude and disinclination to move, and was soon fatigued by exertion. Before consulting me, and under the supposition that her change of colour was occasioned by digordered liver, she had taken a few doses of calomel; without, however, clearing the skin in the slightest degree.
I found the tongue clean, the pulse quiet and regular, and the secretions in good order: there was, indeed, no symptom indicating disease, sare the state of the skin. I prescribed, in turns, steel, quinine, nitric acid with cascaprescribed, in turns, steel, quinine, nitric acid with cascadiet, with exercise in the open air, and a change of atmosphere as soon as convenient. She pursued this plan with some benefit to her strength, but with none to her complexion, for two months, during which time the symptoms did not materially change. One morning in April, she fainted suddenly whilst dressing. Early in June, I urged her to go to town, principally for change of air, and to obtain a further opinion on her case.

In London she saw Dr. Willians, and afterwards Dr. Addison. They pronounced the case to be one of suprarenal disease, and ordered salicine, cod-liver oil, and a residence in a dry locality. These medicines she took for a time, with uncertain benefit; and went to Hampstead. Her colour continued to darken, and occasional blotches appeared on the limbs, as if, says my informant, they had been made with a tar-brush. At Ilampstead, she had one or two attacks of romiting, coming on suddenly, and passing away as soon; and occasional faintness. In the beginning of August, she removed to Bognor, on the south coast; and, immediately on arrival there, she had, says the gentleman who attended her, a severe attack of bilious vomiting and diarrhœa. This was subdued with some difficulty by hydrocyanic acid and opium. Quinine was then prescribed, and she improved for a time. She again ate heartily, and with enjoyment; but could not digest in the upright position; became listless and torpid; felt faint on exertion; and once, a few days before death, on being suddenly raised up, had a slight convulsive fit. On the 14th October, the vomiting returned, without diarrhoea; and she sank exhausted on October 18th.

AUTOPSY, performed four days after death. The body was not much attenuated; it was of a deep brown colour, most observable on the face, hands, and arms. The adipose substance on the chest and abdomen was abundant, and of a deep yellow tinge.

On opening the abdomen, the peritoneum on the left side was found adherent to the omentum; the adhesions were extensive and old. The intestines were pale, undistended, and heaithy. The stomach was also pale, with the exception of a slight blush of vascularity at its large end : it contained about four ounces of green bilious looking fluid. The liver was free from disease, but deficient in colour, and flaccid. The gall-bladder was full of bile. The spleen and pancreas were small, and apparently healthy. There was no disease of the mesentery. The kidneys were somewhat larger and less firm than natural; the internal structure was normal. The suprarenal capsules were hardly traceable, presenting a granulated disintegrated mass, of a yellowish grey colour, mixed with the adipose substance of the part. The uterus was remarkably small. The ovaries were large, and each contained about an ounce of a transparent flnid. The bladder was full of urine.

In the chest, the lungs were small, pale, and flabby. Not more than the usual amount of fluid was found in the pericardium. The walls of the heart were thin, and very flaccid: both cavities were nearly empty; on holding it up, to empty it of blood, a fibrinous clot, quite free from red corpuscles, escaped from some of the large vessels. About two ounces of blood were obtained from the rena cava, perfectly fluid, dark, grumous looking, and destitute of fibrin. There was no alteration of the heart's structure; a few minute spots of ossific deposit were observed on the internal coat of the aorta, above the semilunar valves.

Every organ or viscus presented a bloodless appearance, and was wanting in healthy colour and firmness.

I cannot pretend to make any remarks on the above inexplicable case. The supposition (to me a very doubtful one) that the suprarenal capsules had anything to do with it, does not in any way explain it. The non-fibrinous state of the blood would account for most of the symptoms; but why, when sufficient and nourishing food was 
taken, and apparantly digested, up to the very last (the lenge, liver, and kidneys, properly performing thoir functions), that important fluid was not preserved in its integrity, I am unable to surmise.

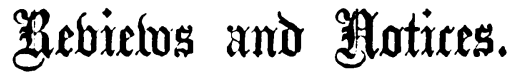

Elements of Axatomy, by Jones Quaiv, M.D. Sixth Edition, edited by WILIIAM SHarPer, M.D., F.R.S. and George Viner Eluis, Professors of Anatomy and Physiology in University College, London. Three volumes. London: Walton and Maberly. 1856.

Demonstrations of Anatoyy: a Guide to the KnowLEge of the Human Body by Dissectron. By Grokge Viner Ellis. Fourth Edition. pp. 832. London: Walton and Maberly. 1856.

Haxdboor of Physiology. By Wimhiam Senhodse KIRKes, M.D., Fellow of the Royal College of Physicians; Assistant-Physician to, and Lecturer on Botany and Vegetable Physiology at, St. Bartholomew's Hospital. Third Edition. pp. 738. London: Walton and Maberly. 1856.

The student who has just commenced his career in the Iondon hospitals, is to be congratulated on the appearance of the new editions of the works whose titles are given above. They are not, it is true, new works, and therefore require none of the obstetric aid of the reviewer to bring them into the literary world. But as books, like all things in the world, have their periods of glory and of decadence, we must say that the works on Anatomy and Physiology before us have as yet no superiors in our country; and that the present editions are fully entitled to all the favour which has been bestowed on their predecessors.

In the Elements of Anatomy, the part on General Anatomy has been carefully revised, and brought down to the state of knowledge at the time of publication, by Professor Sha RPEY. The Descriptive Anatomy has been revised by Professor Eulis; the former co-editor, Professor R. Quain, being prevented by his professional arocations from giving that attention to the work which its importance demands, and which he so ably bestowed on it on a previous occasion. In this department, it is true, much novelty is not to be expected; but we are much gratified at observing that the editors have adopted the views of Professor 0wen with regard to the structure of vertebræ. This is, we believe, a new feature in anatomical works, excepting the monograph of Mr. Holden on Human Osteology. The present edition is published in small octaro-a much more convenient size than that of the former editions; the price is also lower.

Mr. Eurs's valuable aid to the dissector has undergone a careful revision, and is brought down to the present state of knowledge. We observe with satisfaction an inclination on the part of the author to eschew the absurd practice of giving Latin names to parts and structures, for which a snfficiently expressive Saxon appellation exists. Thus the word "axilla" is displaced in favour of "armpit", and the " extremities" are called "limbs". A little more simplification in our medical nomenclature would be desirable.

Dr. KIRK Es's Handbook is, as it has always been, an excellent epitome of our knowledge of physiology. Containing an epitome of the leading doctrines of the science, and written in a generally readable style, it cannot fail to give a very fair insight into the functions of those tissues and organs, of which Quain's Anatomy and Ellis's Demonstrations lucidly describe the structure and arrangement.

Goy's Hospital Reports. Edited by Samoel Winkg, M.D.Londin., and ALFRED PoLAND. Third Series. Vol. ii. pp. 428. London: John Churchill. 1856. THE editors of Guy's Hospital Reports have, in the volume for this year, furnished a series of articles of various but grest interest. We subjoin an autline of the contents of the work.

Mr. Edward Cock first gives an account of a Myeloid Tumour of the Scapula, with a Description of the Growth by Dr. Wrurs. It was connected with the spinous process of the scapula and the acromial end of the clavicle, both which parts were removed. The tumour, which was mostly contained in an osseous shell, consisted in great part of cells with many-sometimes at least a hundred-nuclei. The patient was pregnant during the progress of growth of the tumour; and similar structures to those which it contained were being quickly produced in the fotus.

Drs. LeFrer and OLDHAM furnish the Third Supplemental Report of Guy's Lying-in Charity, from October 1 , 1847 , to October 1, 1854; also a Report of the Lying-in Charity for Twenty-one. Years, from October 1833 to 1854. The Report, which has been drawn up by Mr. S. J. C. Norman, late resident obstetric clerk, contains a large amount of valuable statistical information.

Dr. H. M. HUaHas contributes Select Cases. His first article is a collection of a Black Urine from the Administration of Creasote; a Case of Fever accompanied with Blue Urine; and one of Strumous Peritonitis, in which a black deposit occurred on boiling the urine with the addition of nitric acid. Of the production of blackmess of the urine under the use of creasote or tar, instances are quoted by Dr. Hughes from Drs. McLeod, Weber, and Elliotson. Dr. Weber states that, from the black urine of patients who had been rubbing tar (not tar ointment) over their body, he had obtained creasote by distillation. Dr. Hughes does not attempt any explanation of the coloration, which is a rare effect of the use of creasote, and which sometimes occurs without any apparent cause. In some cases, however, he believes it to be due to the use of iodine.

Dr. Hughes's next case is one of Fatal Intussusception, associated withlumbrici. The next case is one of Emphysema of the Abdominal Parietes from Perforation of the Rectum.

Mr. Thomas Bryant furnishes a paper on Herniz, with an Analysis of 126 Fatal Cases. The author proposes to answer three questions which rery commonly arise :-What form of hernia is most common? What form most frequently requires operation? Which is most fatal ? From the Statistics of the Iondon. Truss Society, and the accounts of 126 cases in Guy's. Hospital, the following conclusions are drawn:-

“1. Inguinal hernia is more common than femoral by $77 \cdot 7$ per cent. 2. Inguinal hernia most frequently commences between 20 and 40 years of age, and femoral between 50 and 70.3. The average duration of inguinal hernia prior to its strangulation is 20 years, of femoral 11 . 4. Inguinal hernia most frequently becomes strangulated before 50 years of age, and femoral after this timo. 5. The average age of persons with strangulated inguinal hernia is 43 , of femoral 55. 6. Femoral hernia requires operation 25.2 per cent. more frequently than inguinal, success in its reduction by the taxis being less froquent. 7 . After operation inguinal hernia is more fatal than femoral by $16 \cdot 6$ per cent. 8 . Trenty-four per cent of cases requir ing operation are recent, and are strangulated on the first descent. 8. Three fourths of these recent cases are femoral. 10. The average period af strangulation in fatal cases of inguinal bernia is $50 \frac{1}{2}$ hours, of femoral $76 \frac{1}{2}$. 11. Half the fatal cases of hernia die within 48 hours after the operation, and four fifths within the first week. 12. Three fourths of the cases which refuse to rally after operation are femoral. 13. Collapse and death after a copious motion is by no means a rare occurrence. 14. Artificial anus much more frequently follows femoral than inguinal hernia. 15. The cause of death in cases of artificial anus is generally exhaustion; that death occurs more rapidly when the intestine is slit open at the time of operation, than when the opening in the bowel naturally follows its return into the abdomen. 16. Sudden collapse and death occasionally occur in cases of hernia which have progressed favourably for many days without any local cause. 17. In about 69 per cent. of fatal cases, peritonitis exists sufficient to produce death; that is to say, lymph in some of its forms is generally effused. 18 . In nine tenths of the cases of hernia, the ilews is the portion of bowel strangulated; and in three-fourths of these, it is part 